Research Article

\title{
Construction of Uniaxial Interaction Diagram for Slender Reinforced Concrete Column Based on Nonlinear Finite Element Analysis
}

\author{
Bedaso Ahmed $\mathbb{D}^{1},{ }^{1}$ Kefiyalew Zerfu $\mathbb{D}^{2},{ }^{2}$ and Elmer C. Agon $\mathbb{D}^{2}$ \\ ${ }^{1}$ Faculty of Civil and Environmental Engineering, Haramaya University, Haramaya, Ethiopia \\ ${ }^{2}$ Faculty of Civil and Environmental Engineering, Jimma Institute of Technology, Jimma University, Jimma, Ethiopia \\ Correspondence should be addressed to Kefiyalew Zerfu; kefiyalewz@gmail.com
}

Received 25 September 2021; Accepted 6 November 2021; Published 23 November 2021

Academic Editor: Chao Wu

Copyright ( $\odot 2021$ Bedaso Ahmed et al. This is an open access article distributed under the Creative Commons Attribution License, which permits unrestricted use, distribution, and reproduction in any medium, provided the original work is properly cited.

Slender reinforced concrete column may fail in material failure or instability failure. Instability failure is a common problem which cannot be analyzed with first-order analysis. So, second-order analysis is required to analyze instability failure of slender RC column. The main objective of this study was to construct uniaxial interaction diagram for slender reinforced concrete column based on nonlinear finite element analysis (FEA) software. The key parameters which were studied in this study were eccentricity, slenderness ratio, steel ratio, and shape of the column. Concrete damage plasticity (CDP) was utilized in modeling the concrete. Material nonlinearity, geometric nonlinearity, effect of cracking, and tension stiffening effect were included in the modeling. The results reveal that, as slenderness ratio increases, the balanced moment also increases, but the corresponding axial load was decreased. However, increasing the amount of steel reinforcement to the column increases the stability of the column and reduces the effect of slenderness ratio. Also, the capacity of square slender RC column is larger than rectangular slender RC column with equivalent cross section. However, the result is close to each other as slenderness ratio increased. Finally, validation was conducted by taking a benchmark experiment, and it shows that FEA result agrees with the experimental by $85.581 \%$.

\section{Introduction}

Reinforced concrete column is a structural member which is used to carry primarily compression loads. It may be short or slender (long) depending on the slenderness ratio of the column. Short column is a column which can resist axial force and moment which is greater than or equal to axial and moment capacity of column cross section. However, slender column is a column which its section resistance is reduced by second-order deformation (buckling) of the column [1]. In addition, previous works showed that the compressive strength, steel reinforcement, and dimensions of cross sections of columns can directly affect the capacity of the column [2]. Slender column may fail either material failure or instability failure. Instability failure will occur as the effect of slenderness of the column increases. The use of slender reinforced concrete column is increasing to keep the aesthetic of the building and get the sufficient space inside of the building [3]. So, analysis and design of this column is considering the second-order deformation necessary. Mac Gregor also recommends that the column should be designed to carry the axial load and moments that account the effect of second-order deformation [1].

Different country codes set on how to consider the second-order effect in the design of slender reinforced concrete column. For example, Euro code- 2 recommends second-order nonlinear analysis and simplified methods such as second-order analysis based on the nominal stiffness method based on estimation of the curvature [4]. Other methods such as the long column reduction factor method and the complementary moment design method also could be used. Except second-order nonlinear analysis, the all other methods use approximate empirical equation to account for the second-order deformation of the 
column. Although some of empirical equation does not account effect of cracking, the others account effect of cracking at location of maximum moment only cracking of the column reduces the flexural stiffness of the column. Since the crack will not form only at the location of the maximum moment, nonlinear analysis of the slender column which accounts the effect cracking throughout the length is needed.

Slender reinforced concrete column may fail in material failure or instability failure. Instability (buckling) failure is a common problem which cannot be analyzed with firstorder analysis. Because geometry, material properties (stress-strain relationship) and large deformations are nonlinear, and hence, nonlinear analysis should be performed to get better result $[5,6]$. For acceptable analysis and design of slender reinforced concrete columns, detail investigation of second-order effects for taking into account a total bending moment. A recent research indicates that an approximate method for calculating the secondorder moment is not always results the safe side of the design. Relatively, a discrete model which take account the $\mathrm{x}$-sectional nonlinearity, nonlinear behavior of concrete in compression, influence of cracking, and tension stiffening provides fair results [7].

In the design of the slender column using the above listed design method, the tensile strength is ignored, though the member carries small tensile stress due to tension stiffening. So, investigating the behavior of slender reinforced concrete column under nonlinear analysis including effect of cracking and tension stiffening effect is very important. Many researchers did different research studies on this area, such as Kim and Kwak did a nonlinear behavior of slender reinforced concrete column [3]. Cleason and Gylltoft also conducted experimental and FE analysis of the slender concrete column subjected to eccentric loading [8]. Rodrigues et al. worked on failure behavior modeling of the slender reinforced concrete column subjected to eccentric loading [5]. However, none of them study construction of uniaxial interaction diagram for slender reinforced concrete column using nonlinear FE analysis.

In this paper, construction of an interaction diagram for uniaxial slender reinforced concrete column using nonlinear finite element software was studied. So, the effect of cracking throughout the length of column and effect of tension stiffening on the uniaxial interaction diagram is also considered in this study.

\section{Material Model}

2.1. Concrete. Concrete exhibits nonlinear stress-strain response mainly because of microcracking. Cracks are oriented as the stress field and generate the failure modes [9]. In tension, failure localized in a narrowband; stressstrain behavior is characterized by sudden softening accompanied by reduction in the unloading stiffness. In compression, failure usually begins at the most outside fiber and is more complex, involving volumetric expansion, strain localization, crushing, and inclined slipping. The stress-strain behavior involves ductile hardening followed by softening and reduction in the unloading stiffness. The concrete damage plasticity model has shown good performance in capturing concrete behavior [10]. This model is particularly well suited for reproducing failure modes that are based on tensile cracking and compression crushing [9]. Thus, concrete damage plasticity was used in this study.

2.2. Uniaxial Compressive Strength. Cubic compressive strength of the concrete which was used in this paper is $43 \mathrm{MPa}$. Figure 1 shows the uniaxial compressive stressstrain diagram which is provided on Euro Code for nonlinear analysis was used [4]. The corresponding equation to calculate the nonlinear uniaxial compressive strength behavior of concrete are shown as

$$
\frac{\sigma_{c}}{f_{c m}}=\frac{\left(k \mu-\mu^{2}\right)}{(1+(k-2) \mu}
$$

where $\mu=\varepsilon_{c} / \varepsilon_{c 1}, \quad 0<\left|\varepsilon_{c}\right|<\left|\varepsilon_{c u 1}\right|$,

$$
\begin{aligned}
\varepsilon_{c u 1} & =3.5, \quad \varepsilon_{c 1(\%)}=0.7 f_{c m}^{0.31}<2.8, \\
k & =\frac{1.05 E_{c m}\left|\varepsilon_{c}\right|}{f_{c m}}, \quad E_{c m}=22\left(\frac{f_{c m}}{10}\right)^{0.3}, \\
f_{c m} & =f_{c k}+8 \quad(\mathrm{MPa}) .
\end{aligned}
$$

The concrete damage values were calculated according to equation (3) and used for FEA modeling under this study:

$$
d_{c}=1-\frac{1}{\left(2+a_{c}\right)}\left[\left(2\left(1+a_{c}\right)^{-b_{c} \varepsilon_{c}^{c h}}-a_{c}^{-2 b_{c} \varepsilon_{c}^{c h}}\right],\right.
$$

where

$$
a_{c}=7.873, b_{c}=\frac{1.97\left(f_{c k}+8\right) l_{e q}}{G_{c h}},
$$

where $l_{e q}$ is characteristic length of element.

$$
\begin{aligned}
G_{c h} & =\left(\frac{f_{c k}}{f_{t m}}\right)^{2} G_{F}, \\
G_{F} & =0.073 f_{c m}^{0.18}\left(\frac{\mathrm{N}}{\mathrm{mm}}\right),
\end{aligned}
$$

$$
\begin{gathered}
f_{t m}=0.3016 f_{c k}^{\frac{2}{3}}, \\
\varepsilon_{c h}=\varepsilon_{t o t}-\frac{\sigma_{c}}{E_{c m}} .
\end{gathered}
$$

2.3. Tensile Strength Behavior. To analyze the tensile behavior of concrete, equation (6) was used. This equation was utilized from previous research studies which were expressed by Alfarah [9]: 


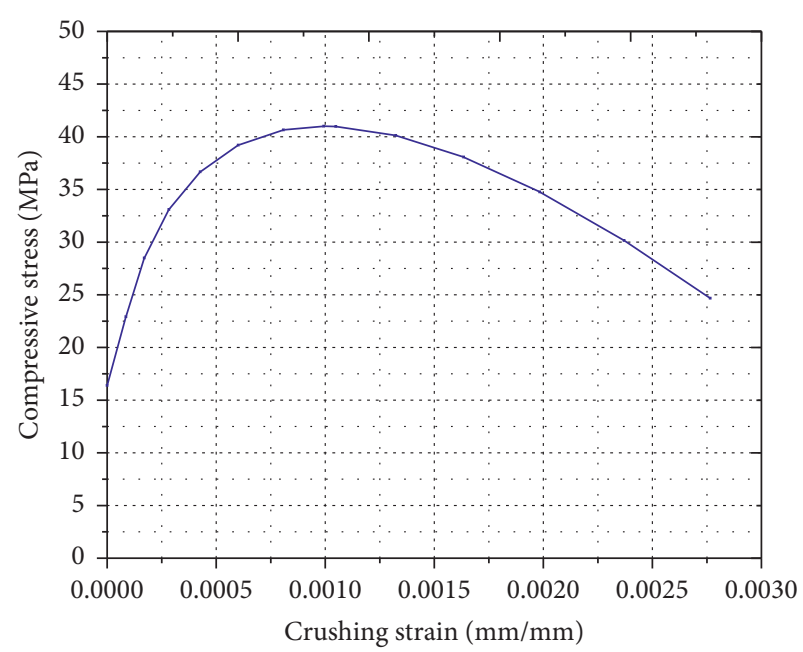

(a)

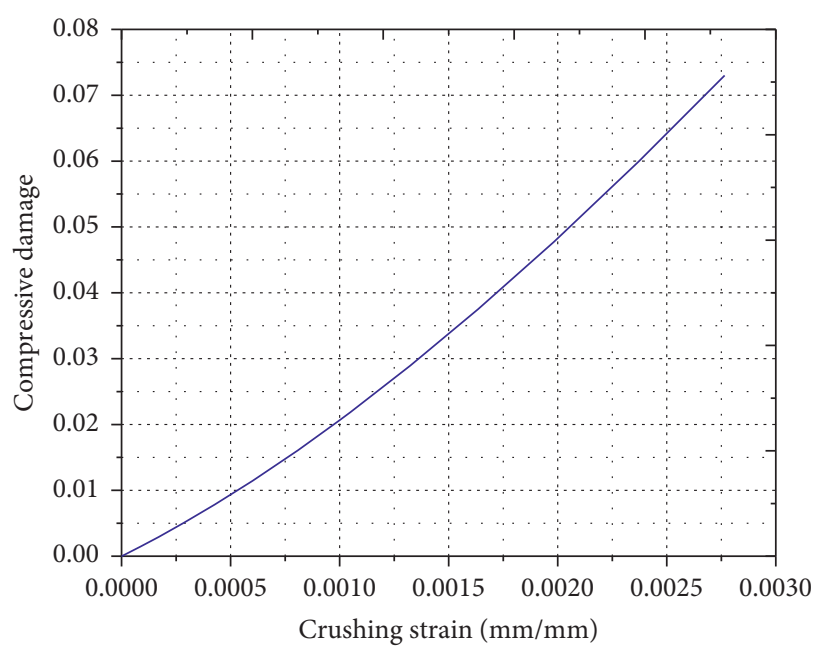

(b)

FIGURE 1: Nonlinear uniaxial compressive strength behavior for concrete. (a) Compressive stress-crushing strain. (b) Compressive damagecrushing strain.

$$
\frac{\sigma_{t}(w)}{f_{t m}}=\left[1+\left(c_{1}\left(\frac{w}{w_{c}}\right)\right)^{3}\right] e^{-\left(c_{2}\left(\frac{w}{w_{c}}\right)\right)}-\left(\frac{w}{w_{c}}\right)\left(1+c_{1}^{3}\right) e^{-c_{2}}
$$

where $c_{1}=3, c_{2}=6.93$, and $\mathrm{w}_{\mathrm{c}}$ is the critical crack opening. From equation (6), it can be clearly understood that $\sigma_{\mathrm{t}}(0)=$ $\mathrm{f}_{\mathrm{tm}}$ and $\sigma_{\mathrm{t}}\left(\mathrm{w}_{\mathrm{c}}\right)=0$. Therefore, $\mathrm{w}_{\mathrm{c}}$ can be considered as the fracture crack opening and given as [9]

$$
w_{c}=\frac{5.14 G_{F}}{f_{t m}} .
$$

In this proposed method, the actual crack spacing was not studied, but single crack per element has been assumed. According to Alfarah et al., the assumption was suitable for global-purpose simulation. After this assumption, in the descending segment of the tensile stress-strain curve, the strain can be obtained in terms of the crack opening from the following kinematic relation given in equations (8) and (9) [9]:

$$
\begin{gathered}
\varepsilon_{t o t}=\varepsilon_{t m}+\frac{w}{l_{e q}}, \\
\varepsilon_{t}^{c k}=\varepsilon_{t o t}-\frac{\sigma_{t}}{E} .
\end{gathered}
$$

As it is discussed in compressive damage variables, the same method was employed also for tensile damage variables, and it is described as

$$
d_{t}=1-\frac{1}{\left(2+a_{t}\right)}\left[\left(2\left(1+a_{t}\right)^{-b_{t} \varepsilon_{t}^{c k}}-a_{t}^{-2 b_{t} \varepsilon_{t}^{c k}}\right],\right.
$$

where $\varepsilon_{t}^{c k}$ is tensile cracking strain which is inelastic strain.

$$
a_{t}=1, b_{t}=\frac{0.453\left(f_{c k}\right)^{(2 / 3)} l_{e q}}{G_{F}} .
$$

Finally, tensile stress-cracking strain and tensile damage variable-cracking strain were prepared and drawn, as shown in Figure 2.

2.4. Steel Reinforcement. All data for the steel reinforcement utilized in this study were adopted from [8]. The input data used for the longitudinal and link steel reinforcement are $7850 \mathrm{Kg} / \mathrm{m}^{3}$ for density and 0.3 for Poisson ratio. The mechanical properties of the steel are depicted in Table 1, and stress-inelastic strain behavior is also presented in Figure 3.

\section{Finite Element Analysis for the Column}

Abaqus 6.13 software was used for modeling of the slender reinforced concrete column. Dynamic explicit, with loading speed of $0.004 \mathrm{~m} / \mathrm{s}$, was used. Four parts were created in the part module. These are plain concrete column, longitudinal reinforcement, lateral reinforcement, and steel plate with the size greater than column dimension. In order to get smooth load-moment interaction diagram, the capacity of the column at eccentricity which is outside the section was used. So, the steel plate enabled us to get the capacity of the column at the eccentricity of outside of the crosssection and also to distribute the concentrated load due to given displacement to the column cross section.

Different analyses were done in validation work using different mesh sizes until the analysis result was conforming to experimental result. Thus, $0.02 \mathrm{~m}$ mesh size gave the best result which conforms to experimental result and takes reasonable running time for the model. Since dependent instances were used, the mesh was done for parts. For the plain concrete column, C3D8R was used which is eight nodes' linear brick, reduced integration hourglass control. The B31, element, which is a first-order three-dimensional beam element, was used for longitudinal reinforcement. However, T3D2, which is a first-order three-dimensional truss element, was used for link reinforcement. Twelve 


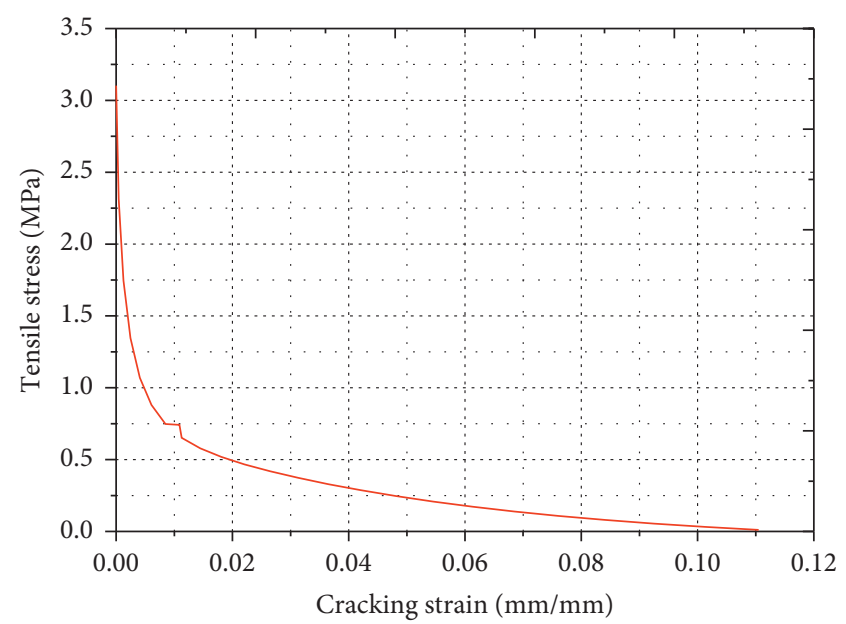

(a)

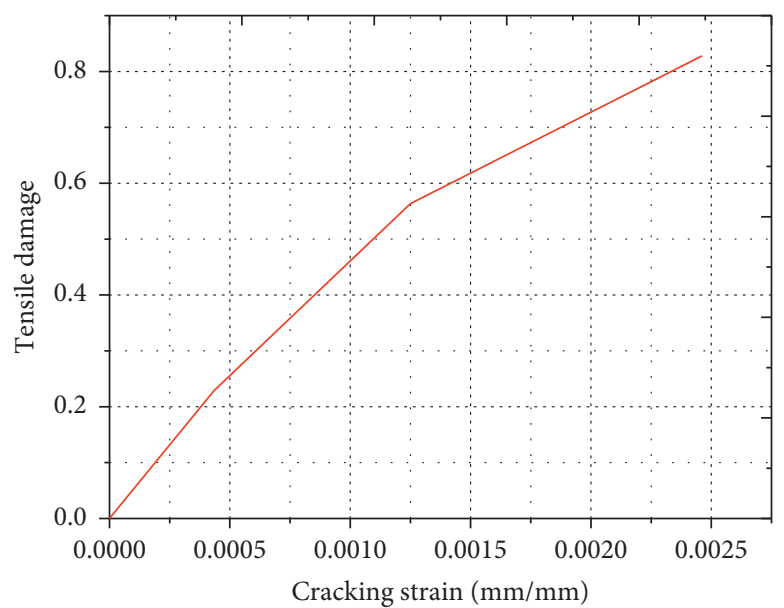

(b)

Figure 2: Nonlinear tensile strength behavior for concrete. (a) Tensile stress-cracking strain. (b) Tensile damage-cracking strain.

TABLE 1: Mechanical properties of steel reinforcement.

\begin{tabular}{lccccc}
\hline Specimen & $F y(\mathrm{MPa})$ & $\mathrm{Fu}(\mathrm{MPa})$ & $\varepsilon S h\left(\%_{\mathrm{o}}\right)$ & $\varepsilon u\left(\%_{\mathrm{o}}\right)$ & Es $(\mathrm{GPa})$ \\
\hline$\phi 16 \mathrm{Ks} 60$ & 636 & 721 & 0.0022 & 0.01 & 207 \\
$\phi 8 \mathrm{Ks} 40 \mathrm{~S}$ & 466 & 620 & 0.004 & 0.012 & 221 \\
\hline
\end{tabular}

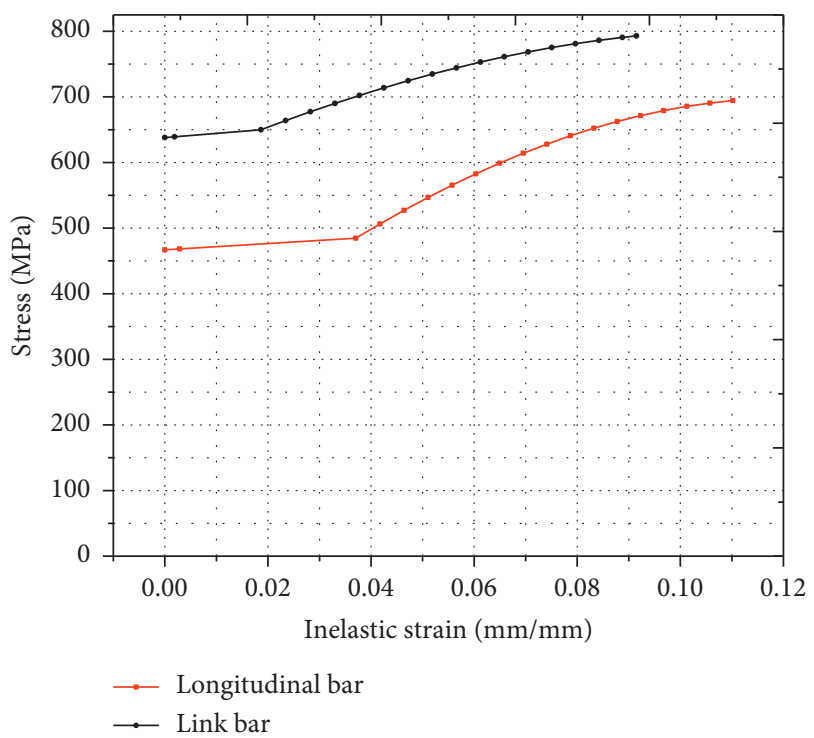

FIGURE 3: Stress-inelastic strain behavior for the steel.

analyses were conducted for each specimen given in Table 2 to get the capacity of the column at different eccentricities. The total analyses were 180 for all specimens.

\section{FEA Results and Discussion}

4.1. Load Displacement. The load-displacement data at different fifteen eccentricities for each specimen were collected. For instance, the load-displacement curve is shown in Figure 4 for SRC1 at eccentricity of $10 \mathrm{~mm}$.
The load-displacement data at different eccentricities were collected and maximum load and its corresponding displacement was taken to get maximum load and moment. Table 3 shows computation of moment from maximum load and its corresponding displacement. For example, for load-displacement curve which is shown in Figure 3, the maximum load is $1196.910 \mathrm{kN}$ and its corresponding displacement is $11.3716 \mathrm{~mm}$.

4.2. Axial Load-Moment Interaction Diagram. The result for the axial load-moment interaction diagram from the current study was drawn, and it is shown in Figure 5.

As shown in Figure 5, as the eccentricities increased, the axial load resistance decreased in a slow manner, but the moment increases rapidly. Especially in the compression control zone, the slope of the curve is gentle which indicates that the difference in compression failure load for two different eccentricities is small.

\subsection{The Effect of Slenderness Ratio on Uniaxial Interaction} Diagram. As indicated in Figure 6, the increase in the slenderness ratio decreases the capacity of pure axial column. Since the nonlinear analysis was conducted, the second-order effect was also included. As slenderness ratio increases, the secondorder effect also increases and results in large displacement. The increment of displacement also increases the moment at the midheight of the column. This is actually happened when the load approached to the balanced failure. At the balanced failure, the reinforced concrete column in compression and tension zones fails simultaneously. For example, for the first specimen, SRC1, with slenderness ratio of 60.62 , the balanced axial load capacity and moment capacity are $774.024 \mathrm{kN}$ and $47.1642 \mathrm{kN}$ $\mathrm{m}$, respectively. However, for second specimen (SRC2) with slenderness ratio of 80.54 , it is $635.928 \mathrm{kN}$ and $52.4527 \mathrm{kN}-\mathrm{m}$. The reduction in axial capacity is $17.84 \%$, and the increase in moment is about $11.21 \%$. However, when the amount of steel increased, the stability of the column is increased and secondorder effect is reduced. 
TABLE 2: Parametric data for the specimens.

\begin{tabular}{lccccccccc}
\hline No. & Specimen & $\begin{array}{c}\mathbf{f}_{\mathbf{c u}} \\
(\mathrm{MPa})\end{array}$ & $\begin{array}{c}\mathbf{f}_{\mathbf{y k}} \\
(\mathrm{MPa})\end{array}$ & $\begin{array}{c}\mathrm{b} \\
(\mathrm{mm})\end{array}$ & $\begin{array}{c}\mathrm{h} \\
(\mathrm{mm})\end{array}$ & $\begin{array}{c}\mathrm{L} \\
(\mathrm{mm})\end{array}$ & $\lambda$ & $\begin{array}{c}\text { No. Bar } \\
(\mathrm{pcs})\end{array}$ & $\begin{array}{c}\Phi_{\mathbf{b a r}} \\
(\mathrm{mm})\end{array}$ \\
\hline 1 & SRCC1 & 43 & 636 & 200 & 200 & 3500 & 60.62 & 4 & 12 \\
2 & SRCC2 & 43 & 636 & 200 & 200 & 4650 & 80.54 & 4 & 0.0122267 \\
3 & SRCC3 & 43 & 636 & 200 & 200 & 5800 & 100.46 & 4 & 12 \\
4 & SRCC4 & 43 & 636 & 200 & 200 & 3500 & 60.62 & 4 & 0.0122267 \\
5 & SRCC5 & 43 & 636 & 200 & 200 & 4650 & 80.54 & 4 & 14 \\
6 & SRCC6 & 43 & 636 & 200 & 200 & 5800 & 100.46 & 4 & 0.0122267 \\
7 & RRCC1 & 43 & 636 & 190 & 210 & 3330 & 60.7 & 4 & 14 \\
8 & RRCC2 & 43 & 636 & 190 & 210 & 4420 & 80.58 & 4 & 0.016642 \\
9 & RRCC3 & 43 & 636 & 190 & 210 & 5510 & 100.46 & 4 & 12 \\
10 & RRCC4 & 43 & 636 & 190 & 210 & 3330 & 60.7 & 4 & 0.016642 \\
11 & RRCC5 & 43 & 636 & 190 & 210 & 4420 & 80.58 & 4 & 0.0122102 \\
12 & RRCC6 & 43 & 636 & 190 & 210 & 5510 & 100.46 & 4 & 0.0122102 \\
\hline
\end{tabular}

SRCC is square reinforced concrete column specimen; RRCC is rectangular reinforced concrete column specimen.
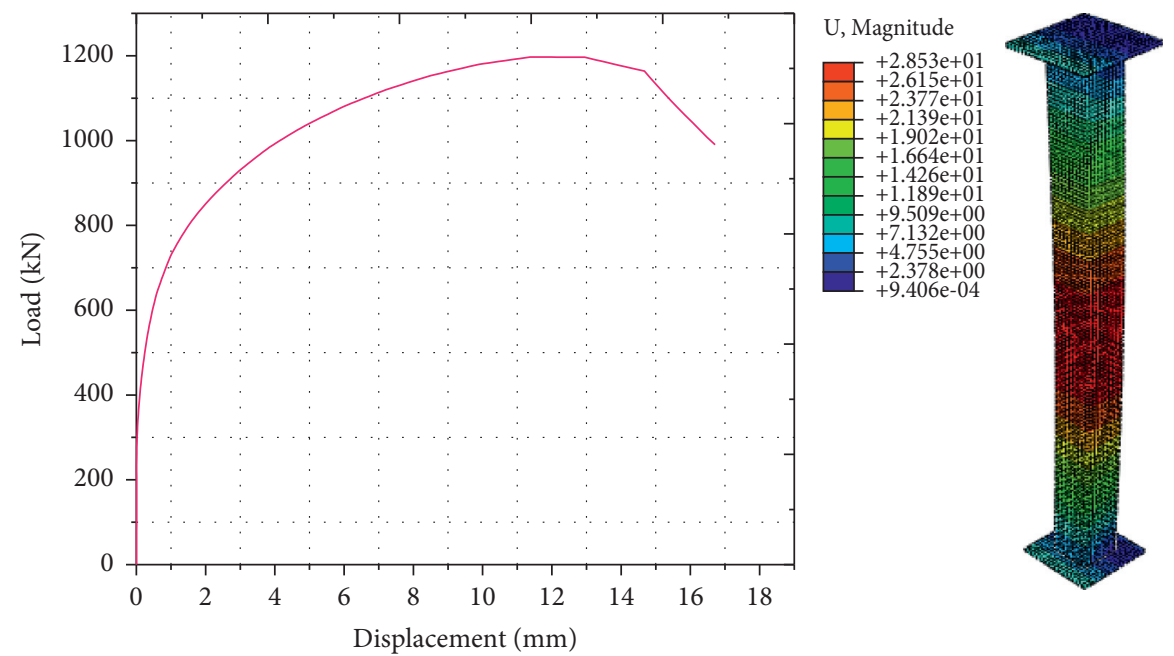

Figure 4: Load-displacement curve for SRC1 column at $e=10 \mathrm{~mm}$.

TABle 3: Axial load and moment for SRC1.

\begin{tabular}{lcccc}
\hline Load, $\mathrm{F}$ & $\Delta$ & $\mathrm{e}$ & $e+\Delta$ & Moment, $M=F^{*}(e+\Delta)$ \\
\hline$(\mathrm{kN})$ & $(\mathrm{mm})$ & $(\mathrm{mm})$ & $(\mathrm{m})$ & 0 \\
1356.26 & 0 & 0 & 0 & 0.0213716 \\
1196.91 & 11.3716 & 10 & 0.0341933 & 25.57988 \\
1066.37 & 14.1933 & 20 & 0.0551304 & 36.46271 \\
835.67 & 25.1304 & 30 & 0.0609338 & 46.07082 \\
774.024 & 20.9338 & 40 & 0.0739412 & 47.16422 \\
617.64 & 23.9412 & 50 & 0.0796088 & 45.66906 \\
568.529 & 19.6088 & 60 & 0.1011345 & 45.25988 \\
430.819 & 21.1345 & 80 & 0.11368 & 43.57066 \\
371.229 & 23.68 & 90 & 0.1308916 & 42.20131 \\
315.741 & 20.8916 & 110 & 0.1448036 & 41.32786 \\
251.086 & 24.8036 & 120 & 0.1549041 & 36.35816 \\
230.099 & 24.9041 & 130 & 0.1638936 & 35.64328 \\
210.903 & 23.8936 & 140 & 0 & 34.56565 \\
-128.361 & 0 & 0 & & 0 \\
\hline
\end{tabular}

4.4. The Effect of Steel Reinforcement Ratio on Uniaxial Interaction Diagram. As shown in Figure 7, increasing the amount of steel raises the compression balanced and also tension failure load. However, as the slenderness ratio increased in the tension control zone, the effect of increasing amount of steel is insignificant. This is caused due to premature or instability failure. As the eccentricity approach to large value and slenderness also increased, the buckling of 


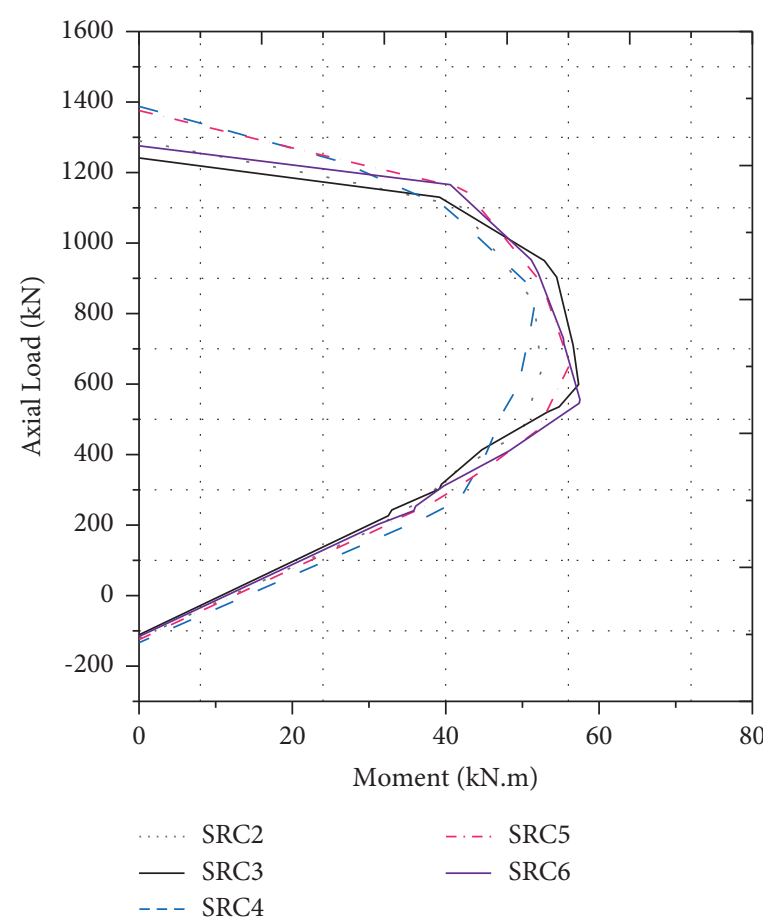

(a)

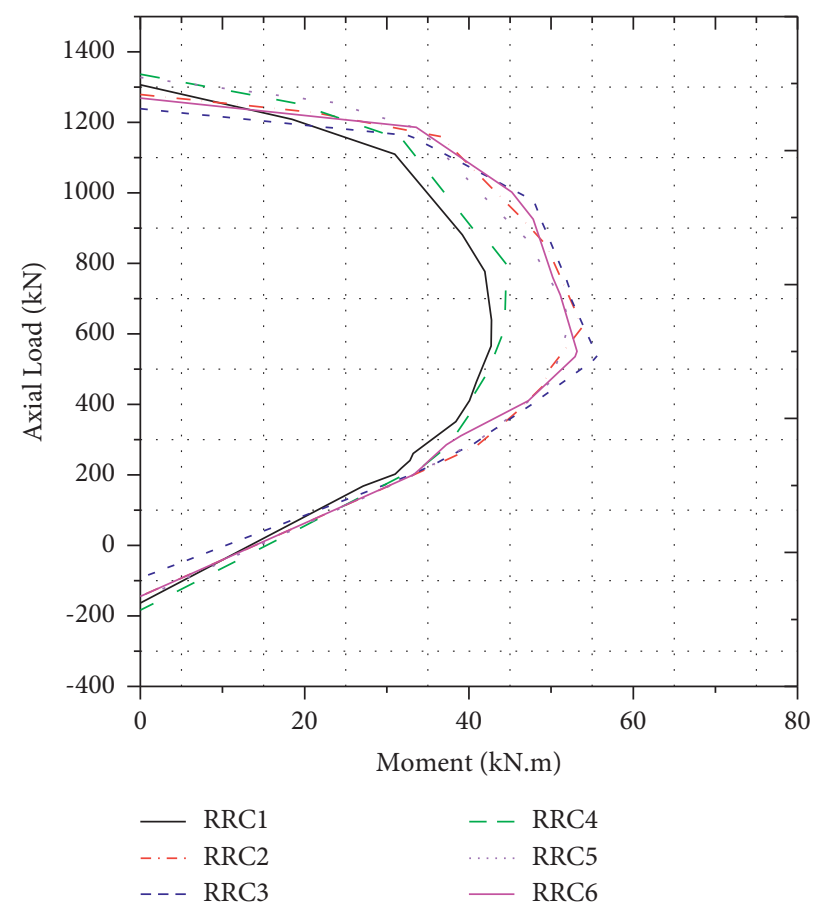

(b)

FIGURE 5: Axial load-moment interaction diagrams. (a) SRC-columns. (b) RRC-columns.

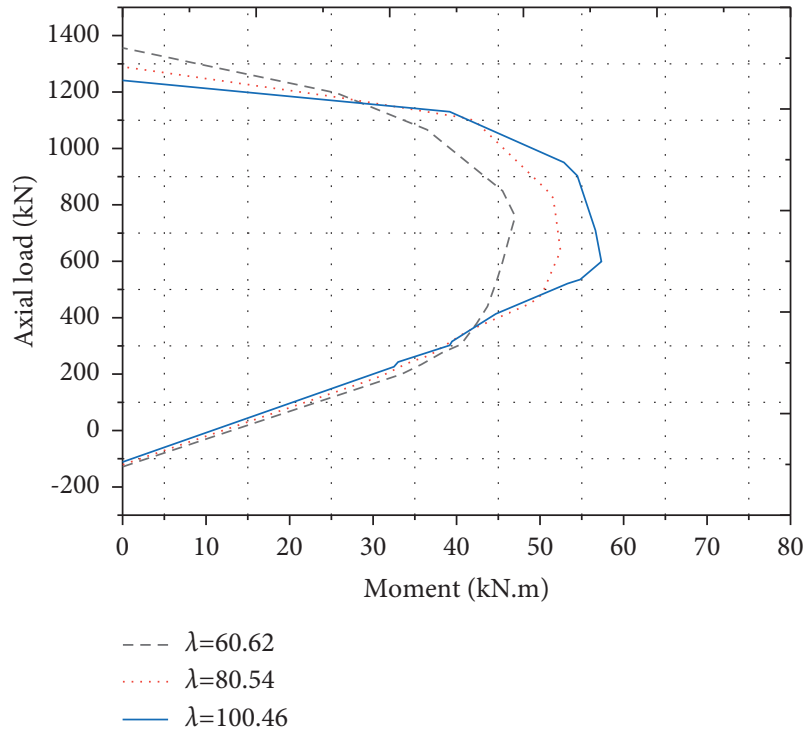

(a)

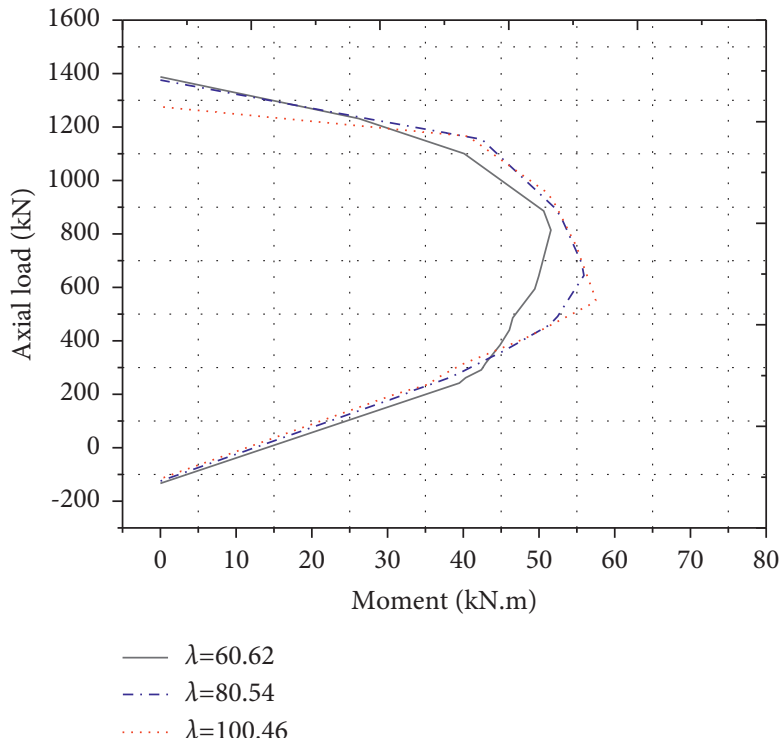

(b)

FIgURe 6: Comparison of axial load-moment interaction diagram based on slenderness ratio. (a) For square column with $\rho=0.01223$. (b) For square column with $\rho=0.01664$. 


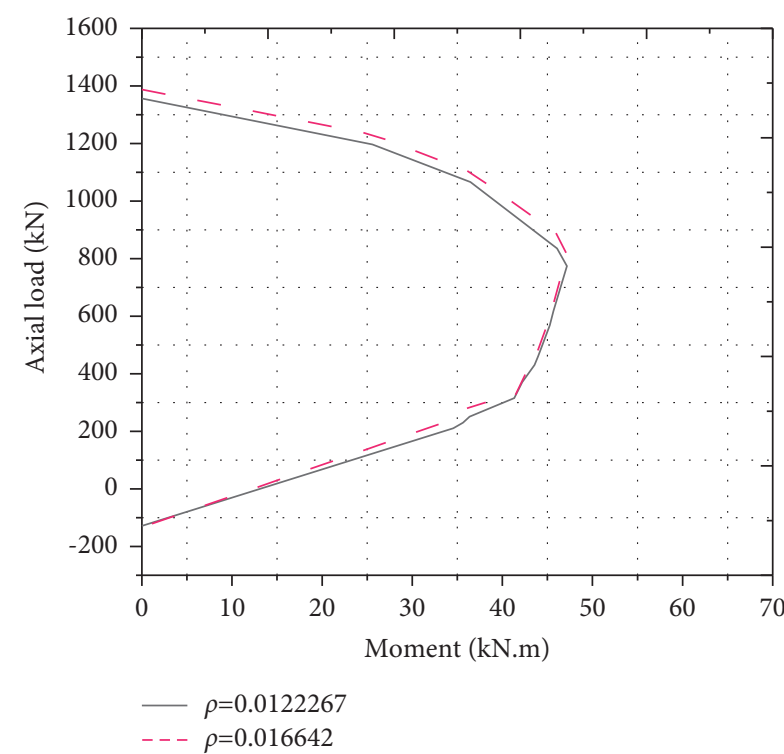

(a)

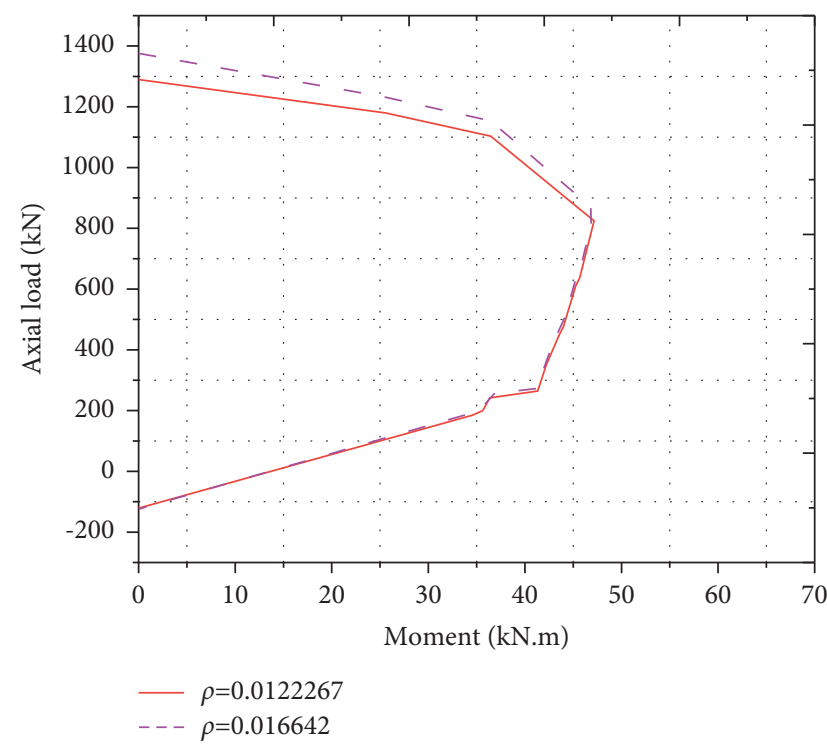

(b)

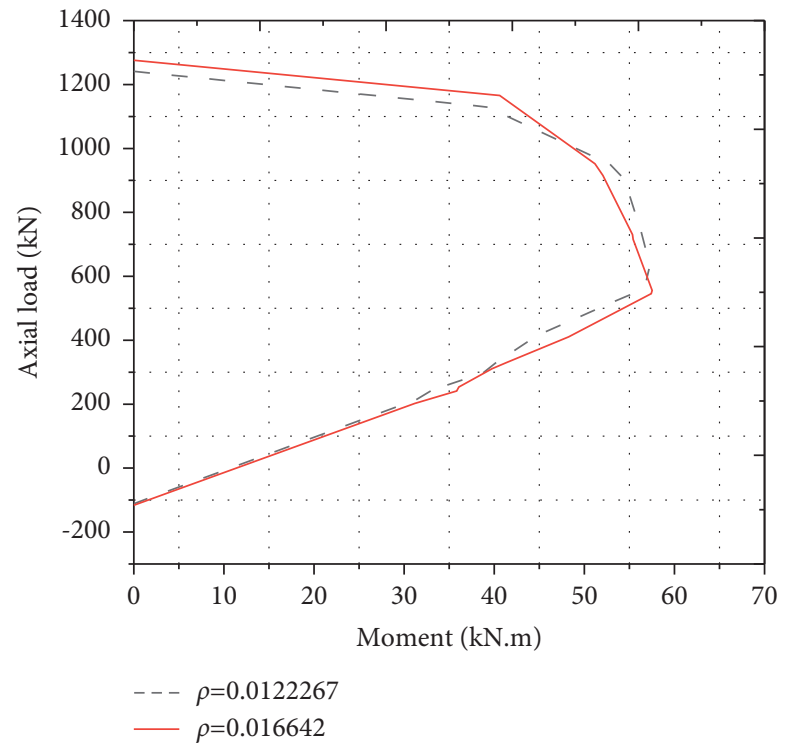

(c)

Figure 7: Comparison of axial load-moment interaction diagram based on steel ratio. (a) For square column with $\lambda=60.62$. (b) For square column with $\lambda=80.54$. (c) For square column with $\lambda=100.46$.

the column will be very large and will result in premature failure.

\subsection{The Effect of Shape of the Column on Uniaxial Interaction} Diagram. The shape of the column has an effect on the capacity of the slender reinforced concrete column. In this study, only square and rectangular reinforced concrete column which have an equivalent area was considered. For the rectangular column, the eccentricity was considered in the minor axis direction so that the column will be uniaxial. The capacity of square reinforced concrete column is larger than rectangular one. However, with increasing slenderness ratio, the effect of the shape diminishes, as illustrated in Figure 8. The effect is the same with the increase in the amount of steel.

\section{Comparative Study (Validation)}

A nonlinear numerical model estimates close results to the experimental ones, which is suitable for use in verification of elements under combined axial load and bending [11]. Before starting modeling of the research specimen, the validation work was done in order to decide on different parameters. By changing loading speed, bulk viscosity, and mesh size, different analyses were conducted and also the load-displacement curve was recorded. 


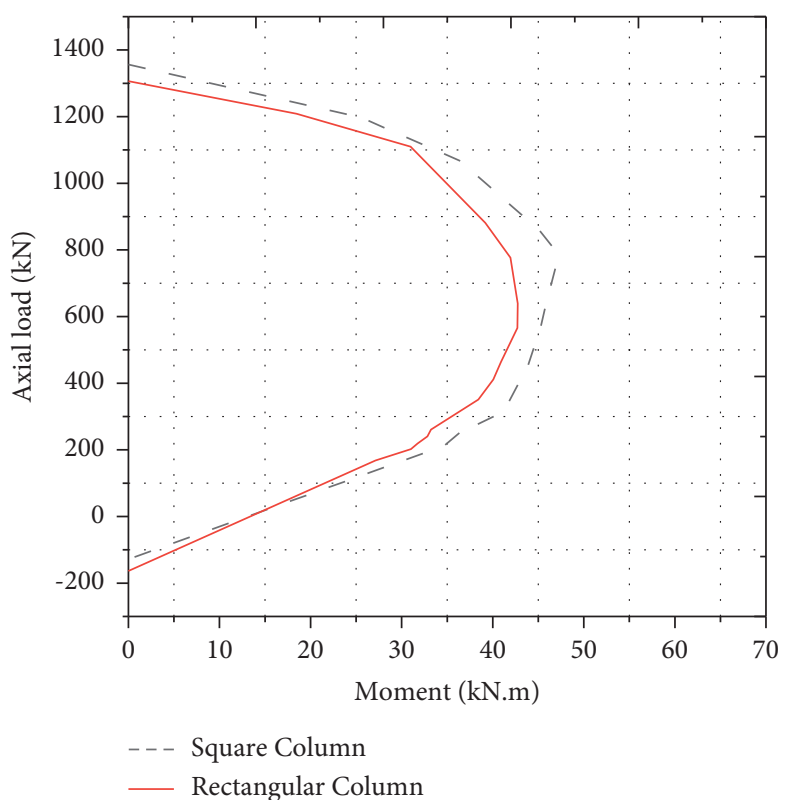

(a)

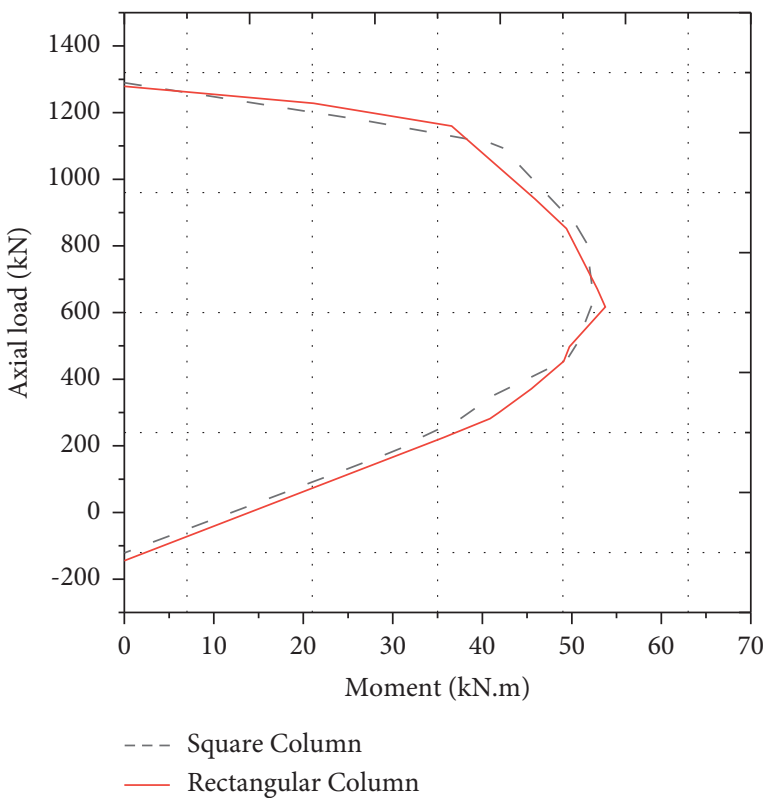

(b)

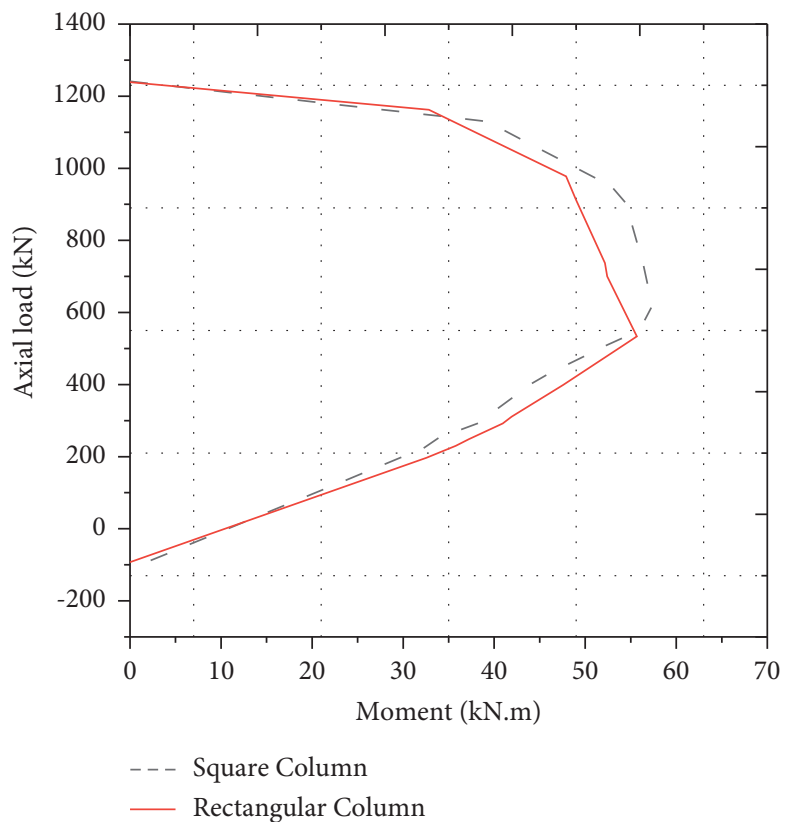

(c)

Figure 8: Comparison of axial load-moment interaction diagram based on shape of the column. (a) Column with $\rho=0.01223$ and $\lambda=60.6$. (b) Column with $\rho=0.01223$ and $\lambda=80.5$. (c) Column with $\rho=0.01223$ and $\lambda=100.46$.

For the validation, Claeson's [8] experimental work which is conducted on high strength slender concrete columns subjected to eccentric loading was utilized. The material data's, geometrical properties, and results from Claeson's experiment that was used for validation are presented as follows:

Three-meter-long square column with cross section of $200 \times 200 \mathrm{~mm}$, which is pinned at both ends

Concrete cover of $15 \mathrm{~mm}$

$4 \phi 16$ longitudinal bars and $\phi 8 \mathrm{c} / \mathrm{c} 130 \mathrm{~mm}$ link bar
$20 \mathrm{~mm}$ eccentricity for the axial load

$$
\begin{aligned}
\mathrm{f}_{\mathrm{cu}} & =43 \mathrm{MPa}, \\
\mathrm{f}_{\mathrm{t}, \mathrm{split}} & =3.7 \mathrm{MPa} .
\end{aligned}
$$

The maximum axial load and the corresponding deflection are $990 \mathrm{kN}$ and $22 \mathrm{~mm}$, respectively.

For illustration purpose, the analysis results were categorized as Valid-1, Valid-2, and Valid-3, as shown in Table 4. 
TABle 4: Categorization of load-displacement curve.

\begin{tabular}{lccc}
\hline Category & Mesh size & Bulk viscosity & Speed $(\mathrm{m} / \mathrm{s})$ \\
\hline Valid-1 & 20 & 0 & -0.0015 \\
Valid-2 & 20 & 0.003 & -0.004 \\
Valid-3 & 20 & 0.0015 & -0.004 \\
\hline
\end{tabular}

TABLE 5: Comparison between FEA and experimental results.

\begin{tabular}{lcc}
\hline Category & Maximum load $(\mathrm{kN})$ & Fexp/FFEA \\
\hline Experimental & 990 & 1 \\
Valid-1(FE) & 1047.34 & 0.9452 \\
Valid-2(FE) & 1204.33 & 0.822 \\
Valid-3 (FE) & 1156.8 & 0.85581 \\
\hline
\end{tabular}

For instance, Valid-1 is the slender reinforced concrete column modeled with mesh size of $20 \mathrm{~mm}$, bulk viscosity of 0 , and compressive loading of $0.0015 \mathrm{~m} / \mathrm{s}$.

Table 5 depicts that the category of Valid- 1 has the load which is nearest to experimental, but the corresponding displacement is very small and far from the experimental, but Valid-3 best conforms to the experimental curve. The maximum load of Valid-3 is $1156.8 \mathrm{kN}$, and the maximum load of experimental is $990 \mathrm{kN}$. So, the experimental is $85.581 \%$ of the maximum load of Valid-3. This indicates that FE result well conformed to the experimental result. Hence, as stated by the previous study, the analysis of the studied model from numerical simulations by using FEM presented reliable results, which can be used in the decision-making processes in engineering projects [12].

\section{Conclusions}

From this study, the following collusions are presented:

Validation between the FEA and experimental work was conducted, in which the experimental result was $85.581 \%$ of the FEA result.

The axial load-moment interaction diagram reveals that, as slenderness ratio increases, the balanced moment also increases, but the corresponding axial load decreases. For example, as slenderness ratio increases from 60.62 for SRC1 to 80.54 for SRC2, the balanced axial load capacity reduces with $17.84 \%$ and moment increases with $11.21 \%$.

Increasing the amount of steel to the column increases the stability of the column and reduces difference in balanced moment due to slenderness ratio. For the same slenderness ratio, increasing the amount of steel also increases all compression failure load, balanced failure load, and tension failure load.

The capacity of square slender RC column is larger than the rectangular slender RC column with equivalent cross section. However, increasing the slenderness ratio reduces the difference in the capacity of the square slender RC column and the rectangular slender RC column.

\section{Abbreviations}

B31: $\quad$ First-order three-dimensional beam element

C3D8R: Eight nodes' linear brick, reduced integration hourglass control

CDP: Concrete damage plasticity

FE: $\quad$ Finite element

FEA: Finite element analysis

FEM: Finite element method

RC: $\quad$ Reinforced concrete

RRCC: Rectangular reinforced concrete column specimen

SRCC: Square reinforced concrete column specimen

T3D2: First-order three-dimensional truss element

Valid: Validation

$\sigma_{c}: \quad$ Compressive stress of concrete

$f_{c m}: \quad$ Mean compressive strength of concrete at 28 days

$\varepsilon_{c u 1}: \quad$ Nominal ultimate strain

$\varepsilon_{c h}: \quad$ Crushing strain

$E_{c m}: \quad$ Secant elastic modulus

$f_{c k}: \quad$ Characteristic cylindrical compressive strength concrete

$d_{c}: \quad$ Compressive damage variables

$d_{t}: \quad$ Tensile damage variables

$G_{c h}: \quad$ Material crushing energies

$f_{t m}: \quad$ Mean tensile strength of concrete

$G_{F}: \quad$ Material fracture energies

$\varepsilon_{\text {tot }}: \quad$ Total strain

$l_{e q}: \quad$ Characteristic length of the element.

\section{Data Availability}

The data used to support the findings in this study are presented in the manuscript.

\section{Conflicts of Interest}

The authors declare that they have no conflicts of interest.

\section{References}

[1] E. O. P. James, G. Mac Gregor, and J. E. Breen, "Design of slender concrete column," ACI Journal Proceedings, vol. 67, no. 1, pp. 6-28, 1970.

[2] S. Khalaf Mohaisen, A. N. Abbas, A. Sabah, A. Associate, and A. S. Ahmed, "Strength and stiffness characteristics of axially loaded reinforced concrete columns with different types of concrete," International Journal of Civil Engineering \& Technology, vol. 10, pp. 10-21, 2019.

[3] H.-G. Kwak and J.-K. Kim, "Nonlinear behavior of slender RC columns," Construction and Building Materials, vol. 20, no. 8, pp. 527-537, 2006.

[4] European Committee for Standardization, Eurocode 2: Design of concrete Structures - Part 1: General Rules and Rules for BuildingsEuropean Committee for Standardization, Brussels, Belgium, 2002.

[5] E. A. Rodrigues, O. L. Manzoli, L. A. G. Bitencourt, P. G. C. dos Prazeres, and T. N. Bittencourt, "Failure behavior modeling of slender reinforced concrete columns subjected to eccentric load," Latin American Journal of Solids and Structures, vol. 12, no. 3, pp. 520-541, 2015. 
[6] N. Y. N. Arya, Second-order FE Analysis of Axial Loaded Concrete Members According to Eurocode 2, p. 100, KTH Royal Institute Of Technology, Stockholm, Sweden, 2015.

[7] Ľ. Fillo, M. Čuhák, and M. Minárová, "Resistance of concrete slender columns," Procedia Engineering, vol. 192, pp. 189-194, 2017.

[8] K. G. Christina Claeson, "Slender high-strength concrete columns subjected to eccentric loading," Journal of Structural Engineering, vol. 124, pp. 233-240, 1998.

[9] B. Alfarah, F. López-Almansa, and S. Oller, "New methodology for calculating damage variables evolution in Plastic Damage Model for RC structures," Engineering Structures, vol. 132, pp. 70-86, 2017.

[10] G. D. Nguyen and A. M. Korsunsky, "Development of an approach to constitutive modelling of concrete: isotropic damage coupled with plasticity," International Journal of Solids and Structures, vol. 45, no. 20, pp. 5483-5501, 2008.

[11] C. Eduardo Luna de Melo and G. S. S. D. Azevedo Melo, "Behavior of reinforced concrete columns under combined axial load and bending in accordance with a nonlinear numerical model," J. Civ. Eng. Archit.vol. 10, pp. 53-63, 2016.

[12] R. M. D. Souza, R. R. Magalhães, and E. T. D. Andrade, "Comparative study of non-linear simulations of a reinforced concrete slender column using finite element method and P-delta," Theoretical and Applied Engineering, vol. 3, no. 1, pp. 1-11, 2019. 